\title{
ANÁLISE DA SAZONALIDADE E DA TENDÊNCIA DE LONGO PRAZO NA VAZÃO DOS PRINCIPAIS TRIBUTÁRIOS DO RIO PARANÁ LOCALIZADOS NO SUL-SUDESTE DO BRASIL
}

\author{
Ana Flávia G. Conceição*, Caroline F. H. Wikuats, Maurício N. Capucim Veronika S. \\ Brand, Leila D. Martins, Jorge A. Martins \\ Universidade Tecnológica federal do Paraná, Londrina, PR \\ *anaflaviagc@ hotmail.com
}

\section{RESUMO}

Neste trabalho, foram analisadas séries de medidas de vazões para os principais tributários da margem esquerda do Rio Paraná em território brasileiro. Os resultados sugerem que há concordância em relação ao aumento na vazão dos rios analisados, porém as taxas de aumento não são uniformes e há tendências diferenciadas entre os rios quando vazões mensais médias, máximas e mínimas são consideradas.

\begin{abstract}
This study analyzed streamflow series for the major left side tributaries of the Paraná River in Brazil. The results suggest that there is agreement regarding the increase in the flow of the rivers analyzed, but increasing rates are not uniform and there are different trends among the rivers when monthly averages maximum and minimum streamflow are considered.
\end{abstract}

\section{INTRODUÇÃO}

As regiões Sul e Sudeste do Brasil têm papel fundamental na produção de energia hidroelétrica. Nessas regiões, estão localizados importantes rios e uma grande concentração de usinas hidroelétricas. Ao mesmo tempo, trata-se de uma região cujos cenários climáticos futuros preveem aumento na precipitação, o que deve impactar diretamente a vazão observada nesses rios e, por consequência, na geração de hidroeletricidade. Tanto a sazonalidade quanto a tendência de longo prazo nas medidas de vazão são fundamentais para se compreender o cenário hidrológico desenhado para a região. Nesse trabalho, foram 
avaliadas as séries de vazão dos principais rios das bacias do sudeste, destacando as tendências de longo prazo e a sazonalidade das mesmas.

\section{METODOLOGIA}

Dados mensais de vazão no período compreendido entre 1931 e 2011, para os principais afluentes do Rio Paraná, foram utilizados nas análises realizadas neste trabalho. Os dados de vazão foram fornecidos pela Agência Nacional das Águas - ANA. Entre os tributários do Rio Paraná, foram analisados os rios Paranapanema, Tietê, Grande, Paranaíba e Iguaçu, conforme ilustrado na Figura 1.

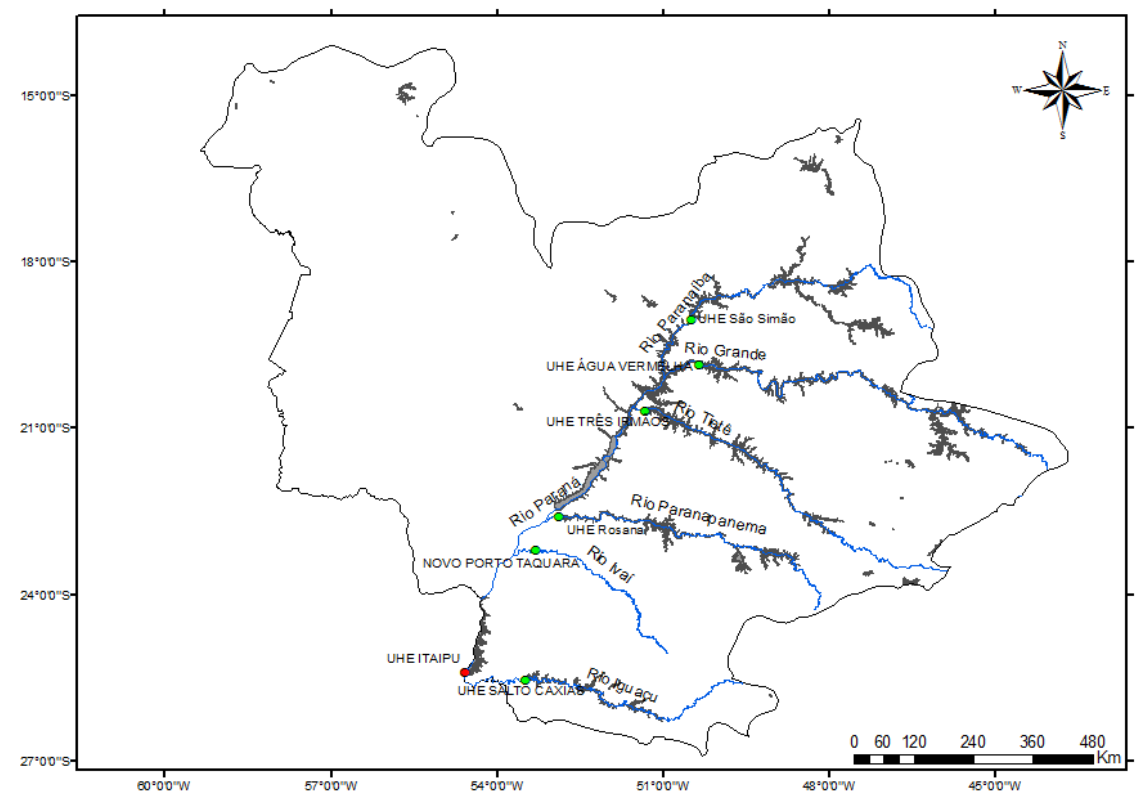

Figura 1 - Mapa com a localização dos principais afluentes do Rio Paraná, destacando os postos de observação de vazão utilizados neste trabalho.

Séries de vazões mensais médias, máximas e mínimas foram analisadas, tanto para a sazonalidade quanto para a tendência de longo prazo. Os resultados de cada afluente foram comparados entre si, comparando as implicações de cenários climáticos futuros.

\section{RESULTADOS E DISCUSSÕES}

Na Figura 02, são mostradas as vazões mensais médias, máximas e mínimas para a localidade da usina de Itaipu no rio Paraná. Embora exista uma sazonalidade com as maiores 
vazões médias no período de verão e menores no inverno, o maior valor histórico mensal registrado é para o mês de junho. Para o rio Iguaçu não se verifica sazonalidade tão bem definida para os valores médios mensais de vazão. São observados três picos anuais, com o maior deles em outubro e os outros dois em fevereiro e junho. Por outro lado, ao longo da série histórica, observa-se que o maior registro de vazão ocorreu no mês de junho e o menor no mês de novembro. Já no caso do rio Paranapanema a sazonalidade é relativamente bem definida para os valores médios mensais de vazão. São observados três picos anuais, com o maior deles em fevereiro e os outros dois em junho e outubro. Por outro lado, ao longo da série histórica observa-se que o maior registro de vazão ocorreu no mês de junho e o menor no mês de março. Para o rio Tietê, verifica-se que a sazonalidade é muito bem definida para os valores médios mensais de vazão, com um pico anual no mês de fevereiro. Ao longo da série histórica, observa-se que o maior registro de vazão ocorreu nos meses de fevereiro e junho e o menor no mês de março. Comportamento semelhante se observa para o rio Grande, exceto para o fato de que o menor registro histórico de vazão ocorreu no mês de janeiro. $\mathrm{O}$ rio Paranaíba também apresenta sazonalidade bem definida para os valores médios mensais de vazão, com um pico anual no mês de março. Ao longo da série histórica, observa-se que o maior registro de vazão ocorreu no mês de fevereiro e o menor no mês de março.

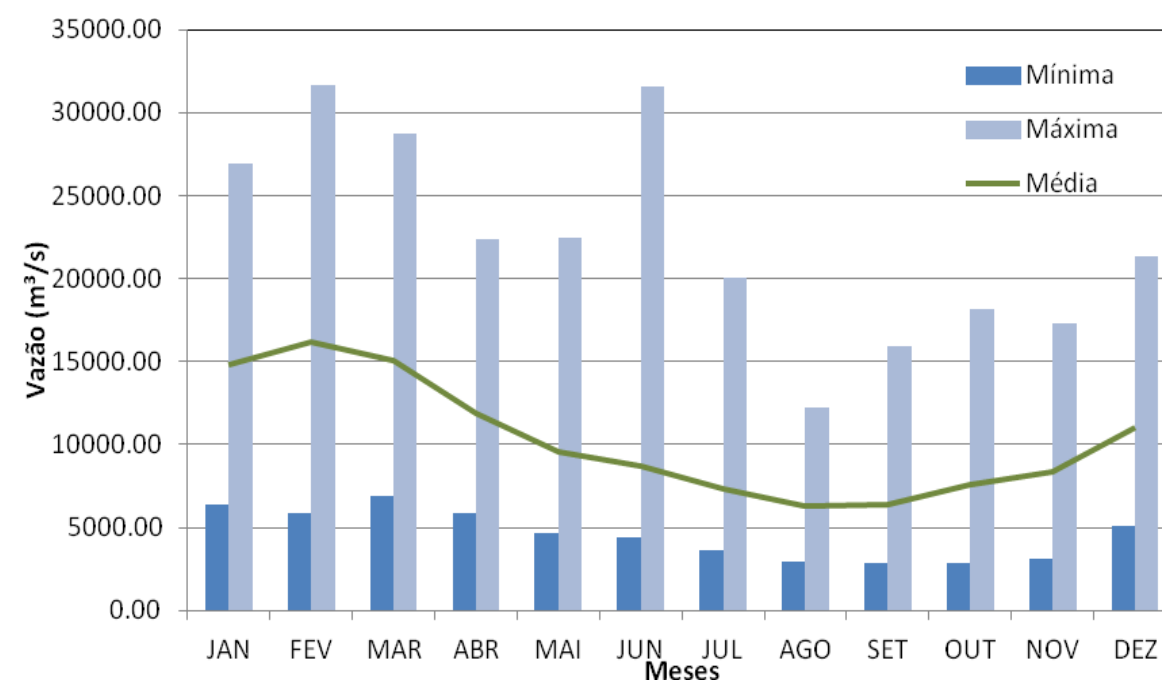

Figura 2 - Vazões mensais máxima, média e mínima para série histórica do Rio Paraná, entre 1931 e 2011. 
Em relação à tendência de longo prazo todos os afluentes analisados apresentaram aumento, tanto para a média quanto para os máximos e mínimos. Entretanto, observa-se diferença considerável na magnitude do valor. Por exemplo, enquanto Tietê, Iguaçu, Paranapanema apresentam taxas de aumento da vazão mensal anual acima de 5\% na década, no rio Grande este valor está abaixo de 2\%. Para as máximas o comportamento é bastante semelhante, porém com uma tendência praticamente nula para o rio Grande. Para as vazões mensais mínimas, o Paranapanema e o Tietê apresentam valor próximo a $10 \%$, enquanto que no Paranaíba o valor fica próximo a $6 \%$ e próximo de $2 \%$ para o Iguaçu e Grande.

\section{CONCLUSÃO}

Os resultados apresentados neste trabalho sugerem que há concordância em relação ao aumento na vazão dos principais afluentes do Rio Paraná presentes nas regiões Sul-Sudeste do Brasil. Todavia as taxas de aumento não são uniformes e há tendências diferenciadas entre os rios quando vazões mensais médias, máximas e mínimas são consideradas. A sazonalidade no regime de vazões também apresenta variação significativa de uma bacia para outra.

\section{AGRADECIMENTOS}

Ao CNPq, Processo n ${ }^{\circ}$ 555768/2010-4

\section{REFERENCIAS}

Agência Nacional das Águas. Bacias hidrográficas. Disponível em: <http://www.ana.gov.br/> acesso em: 09/08/2013.

Brasil. Ministério de Minas e Energia. Plano nacional de energia 2030. Brasília: MME: EPE, 2007. 